\title{
EDITORIAL
}

\section{LONELINESS IN OLD AGE: AN UNADDRESSED HEALTH PROBLEM}

\author{
M. BERG-WEGER ${ }^{1,2}$, J.E. MORLEY ${ }^{2}$ \\ 1. School of Social Work, Saint Louis University, St. Louis, Missouri, USA; 2. Division of Geriatric Medicine, Saint Louis University School of Medicine, St. Louis, Missouri, USA. \\ Corresponding author: John E. Morley, MB, BCh, Division of Geriatric Medicine, Saint Louis University School of Medicine, 1402 S. Grand Blvd., M238, St. Louis, MO 63104, \\ Email: john.morley@health.slu.edu
}

Key words: Loneliness, old age, social isolation, quality of life, depression.

"No one should be alone in old age he thought, But it is unavoidable." --The Old Man and the Sea, Ernest Hemingway

Older persons are more likely to live alone and tend to be less socially engaged. There has also been a decline in religious involvement. This has been perceived to result in a "loneliness epidemic." Declared as a global epidemic by former U.S. Surgeon General Vivek Murthy (1), loneliness and social isolation are reported to occur in approximately onethird or more of older adults with $5 \%$ of those often or always feeling lonely $(2,3)$. Recent U.S.-based research suggests the range is $17 \%-57 \%$ of persons experience loneliness, a figure that increases for those who have mental and physical health concerns, particularly those with heart disease, depression, anxiety, and dementia (4). Loneliness and social isolation have been shown to significantly impact older adults, both physically and emotionally. Areas of the older adult's life that can be negatively affected when the individual is experiencing loneliness and/or social isolation are listed in Table 1. The longterm (greater than four years) effects of loneliness and social isolation can be even more devastating, including; Increased blood pressure, depression, weight gain, smoking alcohol/ drug use, and alone time (5) and decreased physical activity, cognition, heart health, and sleep, stroke and coronary heart disease, in particular (6).

\section{Table 1}

Negative Effects Associated with Loneliness

- Quality-of-life (7)

- Cognition $(28,29)$

- Subjective health (30)

- Stress and depression (31)

- Decreased quality of sleep (32)

- Disability $(33,34)$

- Cardiovascular disease (6)

- Increased use of health care services $(29,35-37)$

- Increased mortality $(29,38,39)$

- Institutionalization (29)
Predictors and risk factors of loneliness and social isolation are numerous, but some may be modifiable. These factors are listed in Table 2 (7-13).

Table 2

Risk Factors for Loneliness

- Living in rural area-being left behind when other migrate

- Poor functional status, particularly in IADLs and cognitive impairment

- Widowhood

- Being female-may be due to increased expressiveness and value on relationships

- Lower income and education-those at higher levels may have more resources/networks

- Urinary incontinence

- Subjective causes - illness, deaths, lack of friends, losses, etc.

-*Depression

- *Living alone

- *Poorly understood by others

-*Wisdom

*Stronger predictors than health, functional status or widowhood

Management of loneliness requires both medical and social interventions. Persons with decreased hearing including those who hear poorly in noisy groups need to be evaluated for hearing amplifiers or hearing aids. Persons with visual disturbances need to be provided with appropriate vision aids. Persons with dual sensory impairment are at particular risk for loneliness (14). Depression can play a major role in loneliness and needs to be treated either with group behavioral therapy especially when minor depression (dysphoria) and medications or electroconvulsive therapy when major depression (15). Cognitive impairment needs to be assessed and where possible reversible causes need to be treated (16). Persons with moderate dementia should be offered Cognitive Stimulation Therapy (17, 18), an evidence-based, non-pharmacologic individual or group intervention.

Developing compassionate social communities are a key approach to dealing with loneliness. Persons who are isolated need to be recognized and attempts made to provide them 
Table 3

ALONE Scale

\begin{tabular}{|c|c|c|c|c|}
\hline A & Are you Attractive (as a friend) to others? & Yes___ & Sometimes___ & No_ \\
\hline $\mathrm{L}$ & Are you Lonely? & Yes_ & Sometimes_ & No_ \\
\hline $\mathrm{N}$ & Do you feel you have No friends? & Yes___ & Sometimes___ & No_ \\
\hline $\mathrm{E}$ & Are you Emotionally upset (sad)? & Yes___ & Sometimes___ & No_ \\
\hline
\end{tabular}

with social interaction. In this case, transportation represents a major component as well as mobilizing youth and other community volunteers to become friendly visitors (via phone or in-person visits). A variety of group therapies such as laughter therapy, reminiscence therapy, horticulture therapy, exercise and dancing can all reduction loneliness (19).

Emotional loneliness requires a different approach. Emotional loneliness is typified by Albert Einstein, who said, "It is strange to be known so universally and yet to be so lonely." It is clear that for a number of reasons, there are persons in the community who have difficulty making friends. They need coaching in behaviors that will help them make friends and to alter their expectations of friends. These people can suffer loneliness in the presence of multiple social contacts (20). It is important to recognize the role of maladaptive social cognition in loneliness as it needs a different therapeutic approach.

Developed by scholars and practitioners at the Central Union for the Welfare of the Aged at Helsinki University in the early 2000s, Circle of Friends(C) is built on a model of group rehabilitation with the aim being alleviation and prevention of loneliness in older adults (21). The group of approximately eight older adults who have self-identified as being lonely or socially isolated meet 12 times over three months with a facilitator for the purpose of making new friends, feeling less lonely, sharing feelings of loneliness with others: experiencing meaningful things together; and transitioning into a selfsupportive group who continues to meet after the initial three months (22). Each session includes three components: 1) Art and inspiring activities with discussion; 2) group exercise and health-themed discussion; and 3) therapeutic writing with sharing and reflecting on issues related to loneliness (23). Evidence for the effectiveness of Circle of Friends $(C)$ has been reported by the founders of the intervention to suggest that the intervention is well suited for delivery with older adult populations living in the community, adult day centers, and residential facilities. Outcomes for participants encompass physical and emotional health and health care utilization. Specifically, in a two-year post-intervention study, $97 \%$ of participants were still living, reported improved subjective health with decreased health care costs and hospitalizations, only $2.5 \%$ had dropped out, and 6 of 15 groups were still meeting (24). Similarly, a later study reports $95 \%$ of participants no longer feel lonely, $45-85 \%$ made new friends, $40 \%$ of the groups continued meetings, and feeling of being needed and psychological well-being improved $(25,26)$.

Through the Geriatric Workforce Enhancement Program (GWEP), Circle of friends (C) is being introduced in the St. Louis, Missouri area. As the first Circle of Friends $(\mathrm{C}$ groups to launch outside of Finland, two organizations have integrated the intervention into programming for older adults. Both funded through the St. Louis Senior Fund, Circle of Friends (C) is being offered at the Association for Aging and Developmental Disabilities and through a collaborative partnership between CHIPS (Community Health in Partnership) and the St. Louis Public Housing authority. Both Groups received training during Summer 2019 and launched multiple groups in the fall at locations in senior centers and housing complexes. Groups continue to meet at both agencies with plans to continue this successful intervention to bring older adults together to build new relationships. In addition, a rural hospital in Perry County and the Family Practice program at Saint Louis University are both providing Circle of Friends groups. Our preliminary observations have suggested that the Circle of Friends is an excellent approach to reduce loneliness.

Physicians and other health and social service providers tend to be poorly trained and equipped to deal with loneliness (27). Patients are seldom asked about loneliness and providers do not have an approach to treating the "problem." There is a need to train medical students and residents and other professionals in recognizing loneliness, e.g., ALONE screen (Table 3) and to manage the problem working together with social workers and the community as so aptly stated by Mother Theresa, "Loneliness and the feeling of being unwanted is the most terrible poverty." Health professionals need to become more aware of the importance of loneliness in older persons.

Disclosures: The authors declare there are no conflicts

\section{References}

1. Murthy V. Work and the loneliness epidemic. Harvard Business Review, September 2017. Retrieved from: https://www.vivekmurthy.com/single-post/2017/10/10/Workand-the-Loneliness-Epidemic-Harvard-Business-Review .

2. Jansson AH, Savikko NM, Pitkala KH. Training professionals to implement a group model for alleviating loneliness among older people-10-year follow-up study Educational Gerontology 2017. DOI: 10.1080/03601277.2017.1420005. 


\section{THE JOURNAL OF NUTRITION, HEALTH \& AGING}

3. Savikko M, Routasalo P, Tilvis RS, Strandberg TE, Pitkala KH. Predictors and subjective causes of loneliness in an aged population. Archives of Gerontology and Geriatrics. 2005;41:223-233.

4. Musich S, Wang SS, Hawkins K, Yeh CS. The impact of loneliness on quality of life and patient satisfaction among older, sicker adults. Geron Geria Med 2015; DOI: $10.117 / 2333721415582119$.

5. Cigna. 2018 Cigna U.S. Loneliness Index. Retrieved from: https://www.cigna.com/ assets/docs/newsroom/loneliness-survye-2018-fact-sheet.pdf

6. Valtorta NK, Kanaan M, Gilbody S, Ronzi S, Hanratty B. Loneliness and socia isolation as risk factors for coronary heart disease and stroke: Systematic review and meta-analysis of longitudinal observational studies. Heart 2016;102(13):1009-1016.

7. Jakobsson U, Hallberg IR. Loneliness, fear, and quality of life among elderly in Sweden: A gender perspective. Aging Clinical and Experimental Research 2005; 17:494-501.

8. AARP. A national survey of adults 45 and older. Loneliness and social connections AARP Foundation 2012. Doi.org/10/26419/res.00246.001.

9. Cohen-Mansfield J, Perach R. Interventions for alleviating loneliness among older persons: A critical review. Am J Hlth Prom 2015;29:e109-e125.

10. Lee E, Depp C, Palmer BW, et al. High prevalence and adverse health effects of loneliness in community-dwelling adults across the lifespan: Role of wisdom as a protective factor. Intl Psychogeriatrics 2019;31:10:1447-1462.

11. Routasalo PE, Savikko N, Tilvis RS, Strandberg TE. Social contacts and their relationship to loneliness among aged people - a population-based study. Gerontology 2006;52:181-187.

12. Savikko N, Routasalo P, Tilvis RS, Strandberg T, Pitkala KH. Predictors and subjective causes of loneliness in an aged population. Arch Geron Geriatr 2005; 41:223-233.

13. Zhang D, Wong C, Sit RWS, et al. Incontinence and loneliness among Chinese older adults with multimorbidity in primary care: A cross-sectional study. J Psychosom Res 2019;127:109863.

14. Harithasan D, Mukari SZS, Ishak WS, et al. The impact of sensory impairment on cognitive performance, quality of life, depression, and loneliness among older adults Int J Geriatr Psychiatry 2019; Nov 17. Doi: 10.1002/gps.5237 [Epub ahead of print]

15. Morley JE. The effectiveness and harms of antidepressants. J Am Med Dir Assoc 2017; 18:279-281

16. Cruz-Oliver DM, Malmstrom TK, Roegner M, et al. Cognitive deficit reversal as shown by changes in the Veterans Affairs Saint Louis University Mental Status (SLUMS) examination scores 7.5 years later. J Am Med Dir Assoc 2014;15:687. e5-10

17. Morley JE, Cruz-Oliver DM. Cognitive stimulation therapy. J Am Med Dir Assoc 2014;15:689-691.

18. Morley JE, Berg-Weger M, Lundy J. Editorial: Nonpharmacological treatment of cognitive impairment. J Nutr Health Aging 2018;22:632-633.

19. Routasalo PE, Savikko N, Tilvis RS, Strandberg TE, Pitkala KH. Social contacts and their relationship to loneliness among aged people - a population-based study. Gerontology 2006;52:181-187.

20. Quan NG, Lohman MC, Resciniti NV, Friedman DB. A systematic review of interventions for loneliness among older adults living in long-term care facilities. Aging Ment Health 2019;11:1-11.
21. Routasalo PE, Arve, Lauri S. Geriatric rehabilitation nursing: Developing a model. Intl J Nurs Prac 2004;10:207-215.

22. Anu J, Tarja Y, Satu H, Pitkala K. Circle of Friends. Group model alleviating loneliness. Retrieved from https://vtkl.fi/toiminta/ystavapiiri

23. Pitkala $\mathrm{KH}$ et al. Leading groups of older people: A description and evaluation of the education of professionals. Edl Geron 2004;30:821-833.

24. Pitkala KH, Routasalo P, Kautiainen H, Tilvis RS. Effects of psychosocial group rehabilitation on health, use of health care services, and mortality of older persons suffering from loneliness: A randomized, controlled trial. J Geron 2009;64A:792-800

25. Routasalo PE, Tilvis RS, Kautiainen H, Pitkala KH. Effects of psychosocial group rehabilitation on social functioning, loneliness and well-being of lonely, older people: Randomized controlled trial J Adv Nurs 2008;65:297-305.

26. Savikko N, Routasalo P, Tilvis S, Pitkala KH. Psychosocial group rehabilitation for lonely older people: A description of intervention and participants' feedback. Int J Older People Nurs 2010;5:16-24.

27. Jovicic A, McPherson S. To support and not to cure: General practitioner management of loneliness. Health Soc Care Community 2019 Oct 2. DOI: 10.1111/ hsc.12869 [Epub ahead of print].

28. Fragliglioni I, Paillard-Borg S, Winblad B. An active and socially integrated lifestyle in late life might protect against dementia. Lancet Neurol 2004;3:343-353.

29. Tilvis RS, Pitkala KH, Jolkkonen J, Strandberg TE. Social networks and dementia. Lancet 2000;356:77-78.

30. Tighuis M, De Jong-Gierveld J, Feskens E, Kromhout D. Changes in and factor related to loneliness in older men. The Zutphen Elderly Study. Age Ageing 1999;28:491-495.

31. Courten E, Knapp M. Social isolation, loneliness, and health in old age: A scoping review. Health Soc Care Community 2017;25:799-812.

32. Shankar A. Loneliness and sleep in older adults. Soc Pschiatry Psychiatr Epidemiol 2019;Nov 15. DOI: 10.1007/s00127-019-01805-8 [Epub ahead of print]

33. Bisschop MI, Kriegsman DM, van Tilberg TG, Penninx BW, van Eijk JT, Deeg DJ. The influence of differing social ties on decline in physical functioning among older people with and without chronic diseases: The Longitudinal Aging Study Amsterdam. Aging Clin Exp Res 2003;15:164-173.

34. Ekwall AK, Sivberg B, Hallberg IR. Loneliness as a predictor of quality of life among older caregivers. J Advanced Nursing 2005;49:23-32.

35. Elaway A, Wood S, Macintyre S. Someone to talk to? The role of loneliness as a factor in the frequency of GP consultations. Br J Gen Practice 1999;49:363-367.

36. Geller J, Janson P, McGovern E, Valdini A. Loneliness as a predictor of hospital emergency department use. J Fam Pract 1999;48:801-804.

37. Russell DW, Cutrona CE, de la Mora A, Wallace RB. Loneliness and nursing home admission among rural older adults. Psychol Aging 1997;12:574-589.

38. Herlitz J, Wiklund I, Caidahl K, et al. The feeling of loneliness prior to coronary artery bypass grafting might be a predictor of short- and long-term postoperative mortality. Eur J Vasc Endovasc Surg 1998;16:120-125.

39. Penninx BW, van Tilburg T, Kriegsman DM, Deeg DJ, Boeke AJ, van Eijik JR Effects of social and personal resources on mortality in old age: The longitudinal ageing study Amsterdam. Am J Epidem 1997;146:510-519. 